\title{
Learning and Experiencing Traditional Culture and Nature of Kanazawa City to achieve Sustainable Development Goals
}

\author{
Aida Mammadova ${ }^{1}$, Juan Pastor Ivars ${ }^{2}$
}

\begin{abstract}
Traditional culture of Kanazawa, is mainly derived from the biological diversity of the city. Linkage between the bio-cultural diversity can be clearly observed in the gardens and tea-ceremonies. Gardens considered as unique hubs for urban biodiversity, provide the habitant for the diverse network of living organism. They facilitate the movement of the species around the urban landscape, i.e became the refuge for the moss and many endangered species in the city. Besides, for the centuries these gardens were linked with the traditional cultures, such as Tea ceremonies, and construction of traditional Tea Houses. In this study we have decided that gardens and tea ceremonies would be ideal places and practices, to raise the awareness on the linkage between the biological and cultural diversity, and conduct participatory educational fieldtrips for 12 international students into five historic gardens of Kanazawa with different designation in the preserved levels. Fieldtrips were as following: sensually observed (visual and listening) of traditional and modern gardens, hands-on practices like cleaning, tea-ceremony performances, traditional architectures and visiting community centers. After the courses students have found a strong linkage between traditional culture with the sustainable living. Besides, the senses like appreciation and attachment to the traditional culture were increased after the fieldtrips, and motivations to take care after those traditional assets was raised. Moreover, students submitted the recommendations and classified the learned aspects within the Sustainable Development Goals (SDGs). Fieldworks into the traditional sites of the city helped to raise the awareness on urban bio-cultural diversity, however on future studies we need to conduct more analysis to link traditional culture with modernized urban development.
\end{abstract}

Keywords: Sustainability, Educational Fieldworks, Traditional Culture, Awareness, Bio-cultural Diversity

\section{Introduction}

\subsection{Japanese Gardens and Biocultural Diversity}

Traditional Japanese culture is mainly derived from the biological diversity of the region, and that linkage between biological and cultural diversity can be clearly observed in the gardens and tea-ceremonies. Gardens for the centuries were considered as unseparated part of traditional Japanese houses (Keane, 2012), and caries the aesthetical and philosophical ideas which has deeply rooted in the spirits of local residents. Gardens which is called niwa in Japanese are broadly classified into the two groups: gardens for visualization and for walking (Engel, 2012). Both groups of the gardens to use less artificial ornaments, and mainly natural landscapes are represented in the threedimensional levels. Gardens create the natural habitat and are consider as the unique hubs for urban biodiversity (Ignatieva, Stewart \& Meurk 2011), as they provide the

$\mid{ }^{1}$ Associate Professor for Organization of Global Affairs, Kanazawa University, Japan

| 2 Research Associate at United Nations University Institute for the Advanced Study of Sustainability Operating Unit Ishikawa/kanazawa, Japan 
habitant for the diverse network of living organism, facilitating to the movement of the rare species around the urban landscape, became the refuge for the moss and many endangered species. The difference of Japanese gardens from the Western style gardens, is that Japanese gardens represent the natural environment in its true form, and try to avoid any artificial constructions or design. Also, gardens are carefully created to be harmoniously coexisted with traditional architecture and housing (Takei \& Keane, 2011; Thacker, 1985). Each house with its traditional architecture should have the connection into the garden with its natural habitats, like small pond, moss, evergreen trees, naturally arranged stones etc.

Besides, gardens played the significant role in Tea Ceremonies which most of the time is conducted inside the Tea Houses of the Gardens (Jolliffe, 2003), and has deeply rooted into the traditional culture. Each guest before entering the Tea House, should pass through the garden, as the way of spiritual purification (Penrod, 2008). Tea ceremonies represent the way of appreciation to the nature and all living beings. Besides, they always carry the small messages, which represent the natural seasonal changes in forms of sweets, flower decorations and views from the gardens. The ceremony is considered "to become a tool for arousing awareness and inner peace so that eventually, through care and repetition, wisdom may arise." (Shaw, 2008)

\subsection{Kanazawa: City of Gardens}

Kanazawa City, the capital of Ishikawa prefecture in Japan, is the next city after Kyoto, which is famous for its gardens. Water canals that run inside the Kanazawa City, are naturally flowing into the houses with gardens, and the amount of water is changing according to the seasons and rain falls. Gardens together with tea rooms, since the samurai times where preserved by the local residents from generation to generations. The city's population is almost half a million people, and the locals for many years cultivated the ability to maintain a lifestyle in harmony with the traditional cityscape and culture (Sasaki, 2003), and it is not surprising that in 2009 the city was designated as a UNESCO Creative City in the field of crafts. Kanazawa City is second city next to Kyoto, in terms of preserving the traditional crafts with 26 verified industries. "Coexistence with nature" is the main goal of the local government policy making and implementation(Kanazawa UNESCO Creative City, 2016). Conservation, revitalization and creation of natural environment in the urban area is a main principle of urban planning and development of the city. After the year of fast economic growth, the city developed the policies for the preservation of the traditional environment and the creation of scenic landscapes, conservation of green areas and water environments, conservation of canals, green slopes and promotion of green city buildings. Later in 2003, the city established policies for the Forest Development, and established the Kanazawa City College of Forestry to develop human resources for forestry management. All these policy measures undertaken by the local government had significant impacts in terms of the conservation of natural habitats in the city (Biodiversity strategy of Kanazawa City, 2017). Besides, the biocultural concepts are strongly manifested in the strategical plans for the city's development and implemented in the local policies of different economic sectors; such as traditional crafts preservation, local cuisine, agriculture sectors and traditional architectural cityscapes preservations. 


\subsection{Previous Achievements}

In our previous studies to teach about sustainability, we have conducted several training courses towards the Sustainable Development Goals and evaluate the sustainability levels of the city's environmental and economic sector. We have already monitored how those sectors depended on each other and functioned in an integrated manner (Mammadova, 2017). However, we were not able to conduct the participatory fieldworks inside the traditional culture of Kanazawa city, which considered being the key for the sustainable bio-cultural preservation and urban development. In this study we have suggested that traditional culture like Tea-Ceremonies and Gardens would help to raise the awareness for the sustainable urban development, and change the attitudes of the learners towards the importance of the traditional bio-cultural preservation. In our approach, we used the fieldtrips activities around the gardens, tea-ceremonies, traditional architecture and communities of Kanazawa City. Students were able to directly experience about the gardens' biological diversity, the cultural linkage between Teaceremonies with garden. Communicate with local people as well as engage with the issues that they face. During the course we have also classified Sustainable Development Goals in each visited sectors.

\section{Methods and Instruments Used}

\subsection{Description of the Fieldtrips}

In 2017, from October to December, we conducted intensive academic courses for the international students to learn about the sustainable urban development and biocultural diversity, inside the Kanazawa City. The main goal of our course, was to raise the awareness about the importance of the traditional Japanese culture for the development of the urban biocultural diversity, and link the that culture with Sustainable Development Goals. Participants were 12 international students from Kanazawa University ( \pm 23 years) with different backgrounds and they had no idea about the city's issues. At the begging of the fieldworks, students were given the basic lectures about the sustainability, social structure and environmental features of Kanazawa City. Fieldworks were designed into five main destinations with different gardens and Tea ceremonies (Table 1), and was guided by the professional specialist who instructed students about the local bio-cultural diversity and issues. One of the garden was main touristic attraction, and others were privately owned small gardens.

Table 1. Visited Gardens and Tea-Ceremony practices

\begin{tabular}{|l|l|l|l|}
\hline 1 & Fieldtrips & Description & Practices \\
\hline 1 & Gyokusen-en & Stroll garden with pond and artificial hills & $\begin{array}{l}\text { Sensual Observation of traditional } \\
\text { gardens }\end{array}$ \\
\hline 2 & Terashima & Flat Garden with Dry pond, House Museum & $\begin{array}{l}\text { Sensual Observation of traditional } \\
\text { gardens }\end{array}$ \\
\hline 3 & Shinrensha & Stroll garden with pond and artificial hills & Hands-on practice and Tea Ceremony \\
\hline Garden & $\begin{array}{l}\text { Stroll garden with pond and artificial hills , Privately } \\
\text { owned }\end{array}$ & $\begin{array}{l}\text { Sensual Observation and Tea } \\
\text { Ceremony }\end{array}$ \\
\hline 5 Sue Garden & Geometric modern garden & $\begin{array}{l}\text { Sensual Observation of modern } \\
\text { gardens }\end{array}$ \\
\hline
\end{tabular}


Gyokusen-en and Terashima gardens were mainly sensually observed gardens through visualization and listening. Whereas, Shinrensha garden, provided the opportunity for the experiential activity to perform hand-on practice in cleaning the garden and observe the diverse biological habitat inside the gardens and link it with the natural living ecosystem. Shinrensha and Senda, gardens provided the opportunity to experience the tea-ceremony and find the linkage between the traditional cultures, through the introduction lectures provided with professional tea-ceremony master. Two different tea ceremonies were conducted, one with Japanese green tea powder Mattcha, and another by Sencha, green tea leaves. Finally, to feel the difference of the traditionally constructed gardens and modernized style gardens, the Sue Garden with symmetrical design was observed.

After the traditional cultural experience, students were taken into the small Community Well-fare organization called Share Kanazawa, to learn about the role of the communities towards the urban sustainability and SDGs. Finally, the SDGs Workshop was conducted to classify all visited sectors with 17 SDGs and submit the reconditions towards their Bottom-up achievements.

\subsection{Data Collection}

During each course students conducted the interviews to the local owners of the gardens. They were requested to find and record the interconnection of each destination with other environmental, social and cultural sectors of the city. After the course, students submitted reports in which they described their experiences. The survey was conducted among the students, to evaluate how the fieldtrips raised the awareness about the issues related with the sustainable urban development and linkage between biological and cultural diversity. Awareness was scored by 1=Very Bad, 2=Bad, 3= Good, 4=Very Good, attitudes were employed by Likert scale of four rates $1=$ Strongly Disagree, 2=Disagree, $3=$ Agree and $4=$ Strongly Disagree, and concerns were rates as $1=$ Not concerned at all, 2 = Somewhat concerned, $3=$ Neutral, $4=$ Concerned, $5=$ Very concerned. Closed-ended questions and multiple choice question were collected, with yes/no replies.

\subsection{Outcomes}

\subsubsection{Reagarding to the Experience of Gardens}

91\% of students replied that Traditional Culture (gardens and tea ceremonies) experiences helped them to understand the concept of sustainability more deeply. $82 \%$ have replied that they became more concerned about the future of the traditional culture. $82 \%$ relied that their attitude towards the traditional culture was change in a better way. The sensual perception as watching was mainly used during the courses. Using the experiential approach during the fieldworks, it was observed by the students that the linkage between the bio-cultural diversity strongly depends on humans' activities (91\%), and without the involvement of the humans these traditional culture would not have survived for such a long time. Most of the students showed the willingness to continue learning the traditional culture, as it "brings the wisdom to act towards the sustainability".

\subsubsection{Regarding to the Implementation of SDG through Gardens Appreciation}

Sustainable development Goals and the outcomes learned from them were 
classified from the students reports in Table 2.

Table 2. SDGs classified by students from the visited sectors (students' transcripts)

1. No Poverty

- The gardens, temples, housing and facilities that we visited were not facing poverty. It's possible that experiencing gardens, tea ceremony and community in a context of wealth can lead towards appreciation of other systems and people groups, which may in turn bring about stronger activism in individuals towards ending poverty.

- There is a consistent link between gardens/tea ceremonies and ending poverty, but it is possible to find work through maintaining gardens, particularly evident in preparations for winter in Kanazawa, and in the way that Share Kanazawa rewards their residents for the work they do on the property. Practicing an appreciation of gardens and tea ceremony can also produce an attitude of understanding and appreciation towards other systems and people.

2. Zero Hunger

- Gardens are a significant part of sustenance, even if there is no fruit, vegetable or livestock production in the garden. Food-producing gardens are certainly related to ending hunger, but I think that recreational gardens like Gyokusen-en are a very good way to introduce people to the concept of sustainable gardening, maintenance and appreciation of natural landscapes. I think biodiversity is also important in ending hunger, as there is still so much reliance on specific food sources, rather than embracing multiple sources of sustenance (for example, just eating white bread versus also eating bread that is made from rye, grains, rice and other sources that might otherwise be neglected).

3. Good Health and Well-Being for people

- Tranquil spaces that gardens have become and the meditative process that can be found in tea ceremony are both conducive to good health and well-being. Perhaps it's subjective, but I think good models for healthy, sustainable lifestyle can be found in both garden appreciation and tea ceremony practice.

- If the building is an indoor living space, the garden is an outdoor living space. It is a place of rest for restoring mind and body fatigue, and serves as play place of child as place of physical fitness training for health. Trees and fences at the garden border can be used to block the outside and ensure privacy inside the garden. The garden also functions as a 'pleasant and healthy environment'. Garden trees and plants supply clean oxygen and can alleviate air pollution to some extent. In addition, the water introduced into the garden can maintain proper humidity and cool in summer.

4. Quality Education

- Although as a class we were prepared to observe, be thinking critically and have our minds expanded, gardens can be learning opportunities. Any experience is a learning opportunity, but I suppose that the gardens and buildings that we went to were set up to let people learn from them, so maybe that's a good principle to draw from them; quality education can be obtained when you go to a place that facilitates your learning, even if it's not a school.

- Education itself can be a sustainable process; by passing on and exploring theory and practices that we know and seeking to understand things that we don't, we can invest in both the present and the future. Even the theoretical model we were exploring through the SDG Games was a practical process, as we were able to actively participate in the interactions of the projects we were all managing.

5. Gender Equality

- Tea ceremonies, for the centuries considered as the place, where everyone will be equal. We saw a great balance of men and women in roles throughout all of the places that we went. I'm 
not sure that this is directly related to gardens or tea ceremony, but it's good to see that there is a place for men or women as tea masters or students. Many of the people responsible for taking care of old buildings or gardens were women too, seen at Terashima and Senda gardens.

6. Clean Water and Sanitation

- Water was such a massive part of all of the gardens and living plants are a big part of sanitation. Although gardens have to be cleaned, they can be really safe spaces for all sorts of life, which we saw clearly at Shinrensha garden through finding not only a turtle, but a crab on the premises. Many species of plants were thriving in the same place too, which shows that gardens can be a great places for life to thrive. Also, gardens can teach us the significance of water and lead individuals to their own deep appreciation of water, hopefully also leading to them respecting their treatment of land and water to keep is clean, or even getting involved with maintenance and sanitation of land or water, even in local community by cleaning their garden or a river or other local space. We also saw the significance of relationship between water systems and gardens at the Sue Water Treatment Plant, and the gardens that were connected to Kanazawa river channels.

7. Affordable and Clean Energy

- Kanazawa has many great examples of ecosystems being able to sustain themselves with little electricity. From the water treatment plant to the river to the gardens that were supported by the river, the ecosystem keeps circulating water and can run with little human or electronic input once established. The sediment settling pool was particularly intriguing at the water treatment plant, showing that even water purification can happen through natural forces.

8. Decent Work and Economic Growth

- Traditional culture provided great work opportunities through maintenance and education. Because gardens and tea ceremonies, continue growing and changing, there is little shortage of work. What is difficult to address in this case is that economic development, alongside technological advancements and shifting social structures and public interests, can mean that old garden systems can lose their apparent relevance or impact, and so they can become places of stagnancy or decline. Yuki-tzuri, for example in one aspect, it has managed to create a sustainable business providing jobs for the preservation of nature for public gardens such as Kenroku-En as well as private gardens for households which are still numerous within Kanazawa.

- In the case of Gyokusen-En, its transition into becoming an open garden for the public as well as a restaurant run by the Nishida family has enabled it to generate its own finances to continue maintaining and preserving the appearance of the garden for future guests. Similarly, Terashima's garden which has become a property of Kanazawa city has achieved a balance by opening a channel of revenue to sustain the property and its garden whilst also providing benefits to the public as a place of historical significance. ... for smaller gardens such as Shinren-Sha's which lack exposure and economic resources, their preservation lies in the hands of the owners.

- By establishing bilateral relations with volunteer groups a beneficial relationship can be established so that the owners can regularly get assistance on maintaining the well-being of the garden at a minimal cost, and in exchange, participants can learn about the landscape and construction of gardens by interacting with the details closely (*means here: that voluntary cleaning activity carried out in Shinrensha garden forms part of a global research activity that its being conducted and implemented by United Nations University Institute for the Advanced Studies of Sustainability Operating Unit Ishikawa Kanazawa, research associate Dr Juan Pastor Ivars together with Kanazawa City and other Universities of Kanazawa). Beyond 
this, establishing a co-operative between private enterprise and the owners could also achieve a similar balance to that of public ownership of the gardens. Ideally, gardens and the associated properties could undergo scheduled maintenance with local businesses, whether through employees or contractors on the condition that it can be sparingly used during various times of the year for those parties as well. There is, of course, economic potential through tourism, whether the gardens have charged entry or not, they may draw tourists to an area, drawing attention and potential business to surrounding establishments.

9. Industry, Innovation and Infrastructure

- The machi-ya (traditional Japanese houses) struck me as innovative, particularly in the walls. Traditional method of wall creation using bamboo, string and mud layering is fascinating. The walls of the property we visited were not made using this old method, and had instead been restored using modern, cheap, quick methods (which apparently functioned a lot better). I hadn't considered that restoration could involve modern methods or materials, and the decisions for the walls seemed perfectly reasonable and more effective. The walls of the machi-ya seemed similar design to the exterior walls around the samurai district which were being covered with straw to protect from snow, which prompted me to consider whether the same alternative material could be considered for those walls. The machi-ya seem like a great place to look for ways to bridge traditional practices and modern practices in innovative ways.

- Gardens are generally attractive places, and so they can become parts of central hubs for other human activity, boosting industry and infrastructure in a somewhat vicarious way. Innovation is also evident and necessary in relation to preservation of old practices and establishments, as old and modern need to find ways to mesh or adapt to each other.

10. Reduced Inequalities

- Share Kanazawa - Moreover, this shows the innovation in how welfare services can meet with business in creating a sustainable concept which benefits the elderly, the mentally disabled and also the surrounding communities which visit the facility for its services, leading to a harmonious relationship.

- Share Kanazawa is mostly run by people with disabilities, meaning they are fully integrated in society. This kind of community raises living standards because people are less lonely and focus on their common interests instead of their differences. Therefore, we can connect this shared community concept to the SDGs about "good health and well-being", "reduced inequalities" and "decent work for all".

11. Sustainable Cities and Communities

- Tea Ceremonies and Gardens can be places to gather. Because they are established environments that require maintaining, and they seem to have general human appeal, they can bring life, peace, work and comfort to communities. It is also great to see in Kanazawa that so many parts of the city are being preserved as gardens, rather than becoming mores spaces for urban development. I think this preservation brings richness and diversity to the city.

- The most memorable place in Kanazawa is "Share Kanazawa". Instead of simply learning about SDGs, people can learn naturally by living there. They can learn to be a member of the community by working together and sharing with people. A high quality of life is exemplified at the share house where residents and workers are not discriminated and given decent wages, training and affordable housing facilities to sustain their lifestyles while also giving them the chance to contribute to the society and economy.

- From the lessons in SDG games workshop, it is clear that none of these goals can be achieved or become sustainable without balance between society, the environment and the economy as all aspects of this world in different chasms require resources from all areas in order to achieve growth. Kanazawa is no exception to this, whether it is through its reuse of 
old buildings to sustainable practices in industry and infrastructure, Kanazawa has found a balance between its sectors in order to meet these SDGs through the collaboration of its citizens, government and businesses. Since its construction, Kanazawa has built itself around the landscape and developed a symbiotic relationship it.

- Rather than destroying old buildings which have confirmed ownership, the city hall has instead designated those buildings to be leased, sold or repurposed for businesses and residence. In some cases, they have been renovated to become hotels and shops to support the growing tourism industry in Kanazawa. In doing so, the city government is trying to reduce waste from the destruction whilst also preserving the historical value of these buildings in Kanazawa, and assisting its tourism industry. From all of these cases, it can be drawn that Kanazawa has been proactive in the development of a better, sustainable society which will last into the future. It has aimed at addressing the existing flaws within its society on all levels and has branched into private and public sectors to create the building blocks of social progression.

12. Responsible Consumption and Production

- Water treatment plant - The slower one was installed in case there is an energy blackout or any other emergency. It doesn't need a lot of energy and is fueled by the hydro energy created by a turbine. This water cleaning station can be linked to the SDG about "clean water and sanitation" since it does not take the water from an exhaustible, but a natural and sustainable source.

- The yukitsuri is a great example of the reliability of some old practices, and the way that the walls had been updated in the machi-ya that we visited was a great example of incorporating new methods into preservation efforts (this also relates to Goal 11).

- A small point from the tea ceremony at Shinrensha has also lingered with me. It was inspiring to hear that some of the equipment he had was just from 100-yen store, but still functioned wonderfully. An item doesn't need to be expensive to hold great value.

\section{Climate Change}

- As natural ecosystems, I think gardens and their preservation is important in appreciating what is at risk with climate change, and learning how to handle the environment well so that we can work against climate change. I also think that tea ceremony is a low-impact activity, and the industries that are behind it may also have minimal negative impact on climate change. 14. Life Below Water

- Kanazawa and its gardens are great examples of sustainable ecosystems with water. Gardens are also great places to gain an appreciation for our relationship, as creatures of the land, with water. The water of the ponds often flows into or derives from the big rivers Saigawa or Asanogawa, making it unnecessary to artificially water the garden.

- This was seen in how the water was handled from the rivers at the treatment facility, as well as how many of the gardens were also dependent on the rivers. Kanazawa seems fortunate to have water in abundance, but I think that keeping these gardens highlights how precious water is, and being able to see it interacting so closely with the city through Asanogawa and Saigawa and the canals around the samurai district prompts me to appreciate the water network. It was also interesting to see that not all gardens depended on the same network, such as the dry garden design at the Terashima home, or the spring water pond at Shinrensha.

15. Life on Land

- This goal is reflected well in maintaining and experiencing the small, diverse little ecosystems that the many gardens in Kanazawa are. I think gardens are quite closely linked with preservation and appreciation of biodiversity. Preservation was certainly a strong concept in cleaning the temple garden, not only in the fact that we were doing general maintenance, but 
in the process of the maintenance itself.

- Just as gardens can give us an appreciation for our relationship with water, I think that they can give an even bigger appreciation for our relationship with life on land. We can see massive diversity in gardens and learn how to interact well with the environment, as well as learn how to treasure it.

- The very first thing that garden has been giving to us is the connection with nature. In details, it brings us much closer to the wildlife by getting us focus and care for the creatures around, even it's the small piece of rock.

16. Peace, Justice and Strong Institutions

- I think a big motivating factor of sustainability is appreciation. This is not based on anything but experiences, but I think that appreciation leads to caring, understanding and action, which is really significant in both individual and universal senses of sustainability. As a basic example, I've found myself far more aware of my water usage since the excursion to the water treatment facility; it deepened my appreciation that a stable supply of drinkable water is a precious and vital resource, and therefore important to use and consume considerately and sustainably. Appreciation, I've found, often comes quite potently when one embarks away from what is familiar to them, or is otherwise exposed to the unfamiliar. Perhaps they then recognize how that experience is different from what they considered normal or familiar, or different from what they expected, and form a sense of appreciation for the familiar thing, the unfamiliar thing, or both.

- Tea ceremonies and gardens can be great places for calm contemplation, and I think many of the traditional gardens in Kanazawa are established to facilitate such a mindset, as well as to refresh the mind, body and soul. Tea ceremony is also based on such principles.

17. Partnerships for the Goals

- Just as individuals can be changed by a garden or tea ceremony experience, I think cities and even nations can be strongly influenced by the identity that they can find in the gardens they contain, whether it be traditional, meditative gardens, gardens with a strong relationship to a function like the water treatment plant, or gardens that are attached to housing or plant nurseries or zoos. Cities, organizations and nations can form relationships and, hopefully, partnerships through gardens and the way that they are handled.

- This was mainly experienced in the SDG Games session, as we saw the models of the outcomes of both working competitively and working cooperatively. The SDG Game itself was a great learning tool. I realize that it was quite simple compared to real-world dynamics of politics, economics and society, and we had the liberty to make quick changes and communicate freely and easily without too much to manage (very little bureaucracy), but it was still interesting to explore the decision-making process and impacts of each small thing on the world.

\section{Discussions}

In the era of globalization, traditional culture is facing many challenges to be lost and forgotten (Douglas, 2004). However, from our course, it was clearly observed that the traditional culture which was preserved and practiced from generation to generation, could increase the awareness and motivations to act towards the sustainability and sustainable development. The senses like appreciation and attachment to the traditional culture were increased after the fieldtrips, and motivations to take care for those traditional assets was raised. Students were able to find the linkage between biological 
and cultural diversity through the fieldtrips into the garden, tea-ceremonies, traditional architecture sites and community centers. Stated by students "traditional culture of Kanazawa city provided us with a lot of opportunities to learn, to work and to think about the environment. We were given the possibility to appreciate nature, reconnect with it and to reflect on ourselves. Moreover, participating at a tea ceremony afterwards made us realize that its key concepts, harmony, respect, purity and tranquility are closely linked to idea of sustainability. Reconnecting with nature reminds us that there should be a harmonious coexistence between people and nature. Cleaning gardens makes us realize how much work needs to be put into such work and our respect for their beauty grows. On top of that, it gives us the opportunity to purify ourselves and calmly observe the tranquility of the nature, which we might want to try to apply to our lives".

Besides, all of those sectors were linked to the SDGs, and showed that sustainability is the interlinked approach and reaching one of the goals, can create the chain reaction and affect other goals. Student comment "SDGs are a set of goals created by the United Nations as a framework of goals for countries and societies to aim towards in developing a sustainable, peaceful world. Through these goals, societies seek to improve their standards of living, quality of life, economic prosperity as well as environmental preservation. From the lessons in SDG games workshop, it is clear that none of these goals can be achieved or become sustainable without balance between society, the environment and the economy as all aspects of this world in different chasms require resources from all areas in order to achieve growth. Kanazawa is no exception to this, whether it is through its reuse of old buildings to sustainable practices in industry and infrastructure, Kanazawa has found a balance between its sectors in order to meet these SDGs through the collaboration of its citizens, government and businesses". Also, students were able to notice about the involvement of locals' citizens and government to act towards SDGs “Across all of its sectors, Kanazawa's ambitions in achieving its SDGs are noticeable, with its policies and population collaborating to create a city with a high quality of life that is sustainable for its people to live in. There is a shared mindset in the residents where everyone works and produces for others and the land to ensure that a peaceful and sustainable society is maintained. At Share Kanazawa, a high quality of life is exemplified at the share house where residents and workers are not discriminated and given decent wages, training and affordable housing facilities to sustain their lifestyles while also giving them the chance to contribute to the society and economy. Moreover, this shows the innovation in how welfare services can meet with business in creating a sustainable concept which benefits the elderly, the mentally disabled and also the surrounding communities which visit the facility for its services, leading to a harmonious relationship. From all of these cases, it can be drawn that Kanazawa has been proactive in the development of a better, sustainable society which will last into the future. It has aimed at addressing the existing flaws within its society on all levels and has branched into private and public sectors to create the building blocks of social progression."

Traditional culture helped the students to understand the concept of sustainability, as stated by another student "visited gardens and tea ceremonies improved the sense of community by giving us the opportunity to clean them in groups, they create jobs and don't exclude workers with disabilities, they don't put any weight on the environment since they are connected to natural water flows and even add to the biodiversity, and 
most of all, they teach us the meaning of sustainability. In order to make something sustainable, it needs to be taken care of constantly and it needs to be fully integrated in or adjusted to the local environment."

Some other comments show that sustainability should start at micro level, and link the Kanazawa City as a model for sustainable cities "we can link Kanazawa city itself as an example of a sustainable city and community. As its own institutions make the best out of the environment, and the available and sustainable resources, it shows a good example to other cities and the world. Instead of looking for solutions on an international and global level, the city first focused on what it could do on a local level. This way, Kanazawa shows that sustainability starts on a reasonably small level".

\section{Conclusion}

Fieldworks into the traditional cultural sites of the city helped to raise the awareness on urban bio-cultural diversity and sustainability in practice. Besides, the senses like appreciation and attachment to the traditional culture were increased after the fieldtrips, and motivations to take care after those traditional assets was raised. Sustainable Development Goals were classified according to each visited sectors, and students were able to acknowledge the importance of the collaborative work to achieve SDGs. However, on future studies we need to conduct more analysis to link traditional culture with modernized urban development.

\section{Reference}

Biodiversity strategy of Kanazawa City, March 2016 (In Japanese). Kanazawa City Homepage. Retrieved April 18, 2017, from http://www4.city.kanazawa.lg.jp/data/open/cnt/3/23326/6/gaiyou.pdf

Douglas, M. (2004). Traditional culture-let's hear no more about it. Culture and public action, 85-109.

Engel, D. (2012). Japanese gardens for today. Tuttle Publishing.

Ignatieva, M., Stewart, G. H., \& Meurk, C. (2011). Planning and design of ecological networks in urban areas. Landscape and ecological engineering, 7(1), 17-25.

Jolliffe, L. (2003). The lure of tea: history, traditions and attractions. Food tourism around the world: Development, management and markets, 121-136.

Kanazawa UNESCO Creative City 2013-2016 Report. Retrieved from http://www4.city.kanazawa.lg.jp/data/open/cnt/3/15014/1/KANAZAWA_2013_2016REPOR T_ENG.pdf. January, 2018

Keane, M. P. (2012). Japanese garden design. Tuttle Publishing.

Mammadova, A. (2017). Sustainability Lessons from Kanazawa City, Japan. European Journal of Sustainable Development, 6(2), 233.

Penrod, (2008) A. Zen and the Art of Tea. Sustainable Development, 6(2), 233.

Sasaki, M. (2003). Kanazawa: a creative and sustainable city. Policy Science, 10(2), 17-30. Retrieved from http://www.ps.ritsumei.ac.jp/assoc/policy_science/102/102_02_sasaki.pdf

Shaw, S. (2008). An Introduction to Buddhist Meditation (p. 336). Routledge.

Takei, J., \& Keane, M. P. (2011). Sakuteiki: Visions of the Japanese garden. Tuttle Publishing.

Thacker, C. (1985). The history of gardens. University of California Press. 